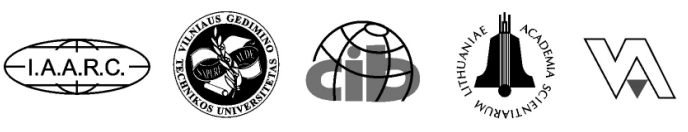

Institute of Internet and Intelligent Technologies Vilnius Gediminas Technical University Saulètekio al. 11, 10223 Vilnius, Lithuania

http://www.isarc2008.vgtu.lt/
The $25^{\text {th }}$ International Symposium on Automation and Robotics in Construction

June 26-29, 2008

ISARC-2008

\title{
AUTOMATED STANDARD WORK TIME DEVELOPMENT IN CONSTRUCTION
}

\author{
Romualdas Tamosaitis \\ Construction Technology and Management Department. Vilnius Gediminas Technical University (VGTU), \\ Saulètekio al. 11, LT-10223 Vilnius-40, Lithuania. E-mail: roma@adm.vtu.lt .
}

\begin{abstract}
This article deals with a new method of forecasting standard work time for specialized worker flows. The methodology of this article is based on the use of information technologies and linear regression analysis. The main advantage of this method is that it allows the user to establish standard work time estimates for specialized worker flows without having to observe each individual task in the project. Once more information about the actual project completion time for each specialized worker team is gathered, the methodology used in this article allows the user to assess the reliability of the standard work time and make additional corrections to the standard work time for individual tasks. Project completion time for each specialized worker team can be determined by the means of Global Positioning System (GPS). As a result, the user of this method is able to evaluate the objective changes in standard work time that occur due to the new technologies or an improvement in equipment and worker skills and reduce the expenditures typically required to calculate standard work time.
\end{abstract}

\section{KEYWORDS}

Forecasting, virtual, standard time, regression analysis, civil engineering

\section{INTRODUCTION}

Currently, there are two main ways to calculate standard work time: time measurement [1], [2], [4], [5], [7], [8] and time forecasting [9-12].

The method offered here employs standard work time forecasting approach. The methodology provided in this article allows for the automated standard work time estimation for specialised worker flows assuming that there is a limited number of tasks to be performed by the same crew with a specific technological equipment. This article also refers to such automated standard work time evaluation as a virtual time standard evaluation. The term "virtual" is used because the standard work time for an individual task is not measured by the traditional method of observation. Instead, standard work time is forecasted on a computer and depends on the total project completion time for each specialized worker group, the number of workers available, the number of individual tasks to be completed, and other task execution conditions.

Virtual time standards (also known as time norms) term was first used in literature in 2002 [9]. The initial method for calculating virtual time standards was based on the minimum sum of square residuals. 
This method was further developed in some publications [10-12], but the regression analysis to evaluate virtual time standards has never been presented in literature before.

The method provided in this article allows the user to evaluate the objective changes in standard work time that occur because of new technologies, equipment and workers skills. However, this method is not applicable in situations where the time needed to complete a task is affected by such unforeseeable factors as extremely bad weather or shortage of materials. If such factors cannot be avoided, a special analysis needs to be performed to estimate the time impact of such factors on the execution of an individual task. Time losses associated with such unforeseeable factors should then be subtracted before the estimation process for standard work time.

In the traditional methods of calculating standard work time, the outlying task duration observations are simply eliminated. Since this method relies on the use of total project completion time, all information associated with an individual project must be either evaluated or eliminated. To determine which projects qualify as outliers (i.e. to establish maximum allowable variation) one should use correlation ratios.

In this method we assume that there is a linear relationship between the time needed to complete an individual task and the number of tasks to be performed.

\section{DEFINITIONS}

Complex process is defined as the sum of all technological processes (performed by the specialized worker flows) that need to be completed to fully achieve a particular goal such as, for example, a completion of a building or a project.

Technological process, on the other hand, is defined as a set of different repetitive tasks that need to be completed as a part of a complex process (e.g. different type floors laying). Individual tasks within a technological process may differ due to the use of different materials, technologies or equipment.
Total labour expenditure in this article is defined as the number of workers multiplied by the total duration of all works completed by the specialized worker flows.

Standard work time for an individual task is defined as the actual labour expenditure (evaluated with a defined probability) needed per one unit of task within a certain technological process (e.g. time needed to lay one square meter of tiles). Standard work time is expressed in man work hours and includes actual work time as well as an allowance for breaks and expected contingencies (e.g. time needed to replace worn out tools).

\section{CONCEPT OF THE VIRTUAL TIME STANDARDS EVALUATION METHOD}

If one could determine the duration of a technological process consisting of $m$ tasks for $n$ projects, where $n \geq m$, one could write a system of equations and mathematically find the unknown variables of the system. Global Positioning System (GPS) can be employed to determine the duration of a technological process through the physical tracking of specialized worker flows from one project to the next.

The system of equations for a technological process is presented below.

$$
\left\{\begin{array}{l}
\sum_{j=1}^{m} K_{1 j} \cdot q_{1 j} \cdot k_{1 j}=T_{1} \cdot F_{1}, \\
\ldots, \\
\sum_{j=1}^{m} K_{i j} \cdot q_{i j} \cdot k_{i j}=T_{i} \cdot F_{i}, \\
\ldots, \\
\sum_{j=1}^{m} K_{n j} \cdot q_{n j} \cdot k_{n j}=T_{n} \cdot F_{n},
\end{array}\right.
$$

In the equations above, $m$ represents the total number of typical tasks $(j=1, m) ; n$ is the total number of projects (or specific time intervals) $(i=1, n) ; K_{1 j}, K_{i j}, K_{n j}$ are total task units for the $j$ th typical task in the first, the $i$-th and the $n$-th 
projects (or as measured at specific time intervals); $q_{1 j}, q_{i j}, q_{n j}$ represent standard work time estimates for the $j$-th task in the first, the $i$-th and the $n$-th projects (or as measured at specific time intervals); $k_{1 j}, k_{i j}, k_{n j}$ are coefficients used to evaluate time losses due to various unforeseeable factors (shortage of materials, bad weather, etc.) in the first, the $i$-th and the $n$-th projects (or as measured at specific time intervals); $T_{1}, T_{i}, T_{n}$ represent the total duration of a technological process in the first, the $i$-th and the $n$ th projects (or as measured at specific time intervals); $F_{1}, F_{i}, F_{m}$ represent the total number of workers in the first, the $i$-th and the $n$-th projects (or at specific time measurement intervals).

The standard work time is always more than zero, therefore:

$q_{i j}>0,(j=1, m)$.

The system of equations presented in (1) can be easily simplified into a linear multiple regression system of equations. This system can then be solved using the traditional methods of linear regression analysis.

To start with, we should express the known independent variables as constants:

$x_{i j}=k_{i j} \cdot K_{m j}$,

where $x_{i j}$ is a constant that represents the total task units and work conditions in the $i$-th project of the $j$ th technological process.

$y_{i}=F_{i} \cdot T_{i}$,

where $y_{i}$ is a constant that expresses labour expenditures in man hours.

After making these changes, we may rewrite formula (1) as:

$$
\left\{\begin{array}{l}
\sum_{j=1}^{m} x_{1 j} \cdot q_{b j}=y_{1}, \\
\ldots, \\
\sum_{j=1}^{m} x_{i j} \cdot q_{b j}=y_{i}, \\
\ldots, \\
\sum_{j=1}^{m} x_{n j} \cdot q_{b j}=y_{n},
\end{array}\right.
$$

The system of equations, represented in this form, can be solved using traditional linear regression analysis methods.

The goal of remaining calculations is to forecast the best theoretical relationship between $x$ and $y$ through variable $q_{b j}$.

The mathematical formula for the task function is given by:

$\operatorname{Min}(S)=\sum_{i=1}^{m}\left[\hat{y}_{i}-y_{i}\right]$.

The task function expresses the least sum of differences between the theoretical project labour expenditures $\hat{y}_{i}$ and actual project labour expenditures $y_{i}$.

To solve such a problem, we use a well-known method of regression analysis for solving multiple linear regression systems.

\section{STANDARD WORK TIME FORECASTING}

In this case, a linear regression without an intercept will be used to express the theoretical relationship:

$\hat{y}=\sum_{j=1}^{m} x_{j} \cdot q_{b j}$,

Where: $\hat{y}$ is total labour expenditures in man hours for the $i$-th project, $x_{j}$ is total task units for the $j$-th 
task, $q_{b j}$ is the forecasted standard work time for the $j$-th task.

In this case, a more practical matrix method [3] will be used for the regression analysis.

Denote the set of $\mathrm{n}$ projects or measurement values of the dependent variable $y_{i}$ by the $n \times 1$ vector $Y$, the set of $q_{b j}$ unknown forecasting time standard parameters by the $m \times 1$ column vector $Q$ and $n \times m$ centred values of total task units by the $n \times m$ matrix $X$. Then the proposed matrix model can be written down as:

$$
Y=X \cdot Q+e .
$$

Where $e$ is a vector of errors for column $n \times 1$.

The theoretical formula for our calculations will then have the following form:

$$
\hat{Y}=X \cdot Q
$$

The least squares equation for the parameter estimates may be expressed as:

$$
X^{T} \cdot X \cdot Q=X^{T} \cdot Y
$$

Where $X^{T}$ is matrix transpose of matrix $X$.

The inverse information matrix $C$ can be expressed as:

$$
C=\left(X^{T} \cdot X\right)^{-1}
$$

In result, the forecasted standard work time for an individual task can be expressed by formula:

$$
Q=\left(X^{T} \cdot X\right)^{-1} \cdot X^{T} \cdot Y
$$

\section{THE EVALUATION OF STANDARD ERRORS IN VIRTUAL TIME STANDARDS}

The inverse information matrix will be used for the standard error evaluation for both regression models [3]. The standard error of an individual standard work time may be expressed by the following formula:

$S_{b j}=S \sqrt{c_{j j}}$,

Where: $S_{b j}$ is the standard error of the $j$-th task's standard work time, $\mathrm{S}$ is the standard error of the regression model and $c_{j j}$ is the value of the inverse information matrix (11).

For models with intercepts, the standard error of the intercept can be evaluated by the following formula:

$S_{c}=S \sqrt{1 /(n-1)+c_{11} \cdot \bar{x}_{1}^{2}+\ldots+c_{m m} \cdot \bar{x}_{m}^{2}+2 \cdot c_{12} \cdot \bar{x}_{1} \cdot \bar{x}_{2}+\ldots,}$

where: $S_{c}$ is the standard error of the intercept; $n$ is the number of projects; $S$ is the standard error of the linear regression model with an intercept; $c_{11}, c_{m m}$, $c_{12}$ are the values from the inverse information matrix; $\bar{x}_{1}, \bar{x}_{2}, \bar{x}_{m}$ represent the mean amount of work for the first, second and $m$-th task in project.

\section{MEASURING THE FIT OF THE REGRESSION MODEL}

The fit of the regression model can be checked by calculating the correlation index and the standard error of the regression model [6]

The correlation index may be obtained:

$$
R=\sqrt{\frac{\sigma_{1,2, \ldots, m}^{2}}{\sigma_{y}^{2}}}=\sqrt{\frac{\sum_{i=1}^{n}\left(\hat{y}_{i}-\bar{y}\right)^{2}}{\sum_{i=1}^{n}\left(y_{i}-\bar{y}\right)^{2}}},
$$

where: $\sigma_{1,2, \ldots, m}^{2}$ is the variation of theoretical values of labour expenditures $\hat{y}_{i}$ as compared to the mean of real labour expenditures $\bar{y}$ under the influence of $m$ factors; $\sigma_{y}^{2}$ is the variation of real labour 
expenditures $y_{i}$ as compared to the mean of the real labour expenditures $\bar{y}$.

Regression model fit may be also evaluated using the standard error of the regression model.

Square residuals of the regression model $R S S$, total square residuals TSS, and unexplained square residuals $S S R$ must be obtained in order to calculate the standard error of the regression model.

Square residuals of the regression model may be obtained by:

$$
R S S=\sum\left(\hat{y}_{i}-\bar{y}\right)^{2}
$$

Total square residuals may be obtained by:

$$
T S S=\sum\left(y_{i}-\bar{y}\right)^{2}
$$

Unexplained square residuals can be obtained by:

$$
S S R=T S S-R S S
$$

The standard error of the regression model can be evaluated using the following formula:

$\mathrm{S}=\sqrt{\frac{S S R}{n-m}}=\sqrt{\frac{\sum_{i=1}^{m}\left(y_{i}-\hat{y}_{i}\right)^{2}}{n-m}}$,

Where: $n$ - the total number of projects, $m-$ the number of tasks, $y_{i}-\hat{y}_{i}$ - the difference between real labour expenditures and predicted values.

Knowing the standard error for the regression model is particularly useful when assessing the reliability of new project data. If the inclusion of the new project data results in the increased standard error for the regression model, the reliability of the newly gathered data should be checked.

Normally, the standard error of real labour expenditures decreases as new project data is added to the model.

\section{FORECASTING LABOUR EXPENDI- TURES AND PROJECT DURATION FOR SPECIALIZED WORKER FLOWS}

Having evaluated standard work time for each task, we can determine labour expenditures and project duration for future projects. Before that, however, it is necessary to evaluate the variance of labour expenditures $V(y)$.

The principal formula for the variance of labour expenditures can be expressed as follows:

$$
(\hat{y}-\bar{y})=q_{b 1} \cdot\left(x_{01}-\bar{x}_{1}\right)+q_{b 2} \cdot\left(x_{02}-\bar{x}_{2}\right)+\ldots
$$

However, since one task may influence another [3], the variance of labour expenditures can be evaluated by the following formula:

$$
\begin{aligned}
& V(y)=V(\bar{y})+V\left(q_{b 1}\right) \cdot\left(x_{01}-\bar{x}_{1}\right)^{2}+V\left(q_{b 2}\right) \cdot\left(x_{02}-\bar{x}_{2}\right)^{2}+\ldots \\
& +2 \cdot\left(x_{01}-\bar{x}_{1}\right) \cdot\left(x_{02}-\bar{x}_{2}\right) \cdot C\left(q_{b 1}, q_{b 2}\right)+\ldots
\end{aligned}
$$

Where: $x_{01}, x_{02}$ represent the total task units; $V(y), V(\bar{y}), V\left(q_{b 1}\right), V\left(q_{b 2}\right)$ represent variances of $y, \bar{y}, q_{b 1}, q_{b 2} ; C\left(q_{b 1}, q_{b 2}\right)$ is a covariance of $q_{b 1}, q_{b 2}$.

The variances and the covariance can be replaced by the inverse information matrix elements:

$V(y)=s^{2} \cdot\left\{1 /(n-1)+c_{11} \cdot\left(x_{01}-\bar{x}_{1}\right)^{2}+c_{22} \cdot\left(x_{02}-\bar{x}_{2}\right)^{2}+\ldots\right.$

$\left.+2 \cdot\left(x_{01}-\bar{x}_{1}\right) \cdot\left(x_{02}-\bar{x}_{2}\right) \cdot c_{12}+\ldots\right\}$

Hence, labour expenditures can be forecasted by the formula:

$y_{0}(P)=\hat{y} \pm t \cdot \sqrt{V(y)}$

Where $y_{0}(P)$ is labour expenditures with the probability $P$ and t is a t-statistic.

\section{CONCLUSIONS}

1. This article employs virtual time standards methodology and uses regression analysis to forecast standard work time (evaluated with a defined 
probability) without having to observe individual tasks in the projects.

2. The methodology used in this article allows for a quick evaluation of the actual time needed to complete a task, with an allowance for breaks and expected contingencies. Furthermore, it enables the user to evaluate objective changes in the standard work time which may occur as new materials, technologies and human skills are acquired.

3. The standard work time forecasting method outlined in this article is particularly useful when technological processes in construction projects are based on the specialized worker flows. This model is also recommended when the execution of one task is affecting the execution of another task. Virtual time standards forecasting method allows the user to evaluate the duration of future projects while taking into account the links that exist between different specialized work flows. This is something that is very hard to do in practice.

4. The linear regression analysis methodology used in this article is better established and more widely used than other existing standard work time forecasting methods. It is thus more likely that the process of forecasting virtual time standards through the use of linear regression analysis will be more simple and more reliable than other methods discussed earlier [12], [13], [14], [15].

\section{REFERENCES}

[1] Chan D. W. M. and Kumaraswamy M. M. (1996). An evaluation of construction time performance in the building industry. Building and Environment, Vol. 31, No.6: 569-578.

[2] Chatzoglou P. and Macaulay L. (1996). A review of existing models for project management and estimation and the need for a new approach.
International Journal of Project Management, Vol. 14, No. 3: 173-183.

[3] Davies Owen L., Goldsmith Peter L. (1972). Statistical Methods in Research and Production. Edinburgh: Oliver and Boyd.

[4] Dawson, R. J. and Dawson C. W. (1998). Practical proposals for managing uncertainty and risk in project planning. International Journal of Project Management, Vol. 16, No. 5: 299-310.

[5] Harris F. and Mc Caffer R. (2000). Modern construction management. UK, Blackwell Science.

[6] Koop G. (2000). Analysis of Economic Data; West Sussex: John Wiley \& Sons.

[7] Peurifoy R.L., Ledbetter W.B. (1985). Construction Planning, Equipment, and Methods. New Yourk: McGraw-Hill.

[8] Proverbs D.G., Holt G. D. and Olomolaiye P. O. (1999). Factors impacting construction project duration: a comparison between France, Germany and the U.K.; Building and Environment, Vol. 33: 197-204.

[9] Tamosaitis R. (2002). Calendar plans simulation in construction, Vilnius: Technika.

[10] Tamosaitis R. and Gargasaite L. (2002). Virtual time norms in civil engineering; 5 th conference of junior scientists "Lietuva be mokslo - Lietuva be ateities", Vilnius: Technika. 63-72.

[11] Tamosaitis R. and Gargasaite L. (2003). Modelling of virtual time norms for technological processes. In: Modelling and simulation of business systems $(\mathrm{H}$. Pranevicius, E. Zavadskas, B. Rapp (Ed.)), Kaunas University Technology Press "Technologija". 311316.

[12] Tamosaitis R. and Gargasaite L. (2003). Virtual time norms and repetition effect. In 1st International Meeting of Science and Technology of Design Senses and Sensibility in Technology Linking Tradition to Innovation through Design, Lisbon. 1-6. 